\title{
Trauma na gestação
}

\section{Trauma during pregnancy}

\author{
Sérgio Hoffmeister Martins-Costa ${ }^{1}$, José Geraldo Lopes Ramos ${ }^{2}$, Yherar Lavic Guerin Serrano ${ }^{3}$
}

Gestantes vítimas de trauma, fenômeno antigamente raro, têm sido um problema cada vez mais comum a engrossar as estatísticas de morbimortalidade, em especial nos grandes centros urbanos, em geral às custas dos acidentes automobilísticos e do uso de armas de fogo. As mortalidades materna e perinatal relacionadas ao trânsito de veículos automotores podem ser reduzidas de maneira significativa, já que dependem em primeiro lugar de atitudes de prevenção primária tomadas pelos individuos, pelos fabricantes de veículos, pelos engenheiros de trânsito, pelos legisladores e, secundariamente, ao treinamento da equipe de saúde das emergências hospitalares no atendimento das gestantes vítimas de trauma.

A morte de uma gestante ou puérpera vitimada por trauma não entra no cálculo da razão de mortalidade materna. Estes óbitos são classificados como morte "não relacionada" ou "morte materna não obstétrica", diferenciando-se das mortes maternas obstétricas diretas e indiretas por presumivelmente não serem desencadeadas (diretas) nem agravadas (indiretas) pelo estado gravídicopuerpera $^{1,2}$. A exclusão destas mortes do cálculo da razão de mortalidade materna tem sido questionada, principalmente nos países desenvolvidos, onde a prevenção das causas diretas e indiretas é eficaz. Nestes países, em alguns centros o trauma na gestante é responsável por até $46 \%$ das causas de morte materna ${ }^{3}$. A perda fetal em gestantes vítimas de traumas pode alcançar cifras que vão de 4 e $61 \%$, sendo que sua magnitude depende da gravidade do dano e do tempo de atendimento da gestante ${ }^{4}$.

Na população brasileira poucos estudos têm avaliado as repercussões do trauma nas gestantes. Corsi et al. ${ }^{5}$ analisaram retrospectivamente 26 gestantes traumatizadas durante um período de nove anos. A média de idade destas pacientes foi de 23,7 anos. A idade gestacional esteve entre a $10^{\mathrm{a}}$ e a $40^{\mathrm{a}}$ semana, com uma média de 21,5 semanas, estando a maioria delas no segundo trimestre $(46,1 \%)$. O principal mecanismo envolvido foi o trauma abdominal fechado por acidente automobilístico. A mortalidade materna em $11,5 \%$ dos casos envolveu o choque hemorrágico e a fetal foi de 30,7\%, sendo que $37,5 \%$ destes óbitos fetais foram provocados pela morte materna. A principal causa de mortalidade fetal envolveu o descolamento de placenta (50\% dos casos. Neste fascículo da RBGO, Fraga et al. apresentam estudo no qual avaliaram retrospectivamente 13 gestantes vítimas de trauma abdominal grave submetidas a laparotomia na cidade de Campinas entre 1990 e 2002. Quarenta e seis porcento destas pacientes tiveram trauma abdominal penetrante produzido por arma de fogo, com metade destas pacientes apresentando lesão uterina. Em todos os casos nos quais houve lesão uterina os fetos morreram. Não houve casos de morte materna e o obituário fetal total alcançou 30,7\%.

Embora o mecanismo do trauma nas gestantes ou puérperas seja bastante similar ao das pessoas não grávidas, existem algumas diferenças que devem ser ressaltadas. Com o volume uterino aumentado e ocupando a pelve, as vísceras se encontram relativamente protegidas durante os traumas penetrantes, e com o avançar da gestação, o risco para lesões do útero se torna gradativamente aumentado ${ }^{6}$.

O traumatismo penetrante durante a gestação consiste principalmente no resultado de ferimentos por arma de fogo ou arma branca. Neste tipo de trauma a morbidade e mortalidade fetal e materna são bastante diferentes ${ }^{6}$. Numa série de casos na qual se revisaram lesões ocorridas durante os 16 anos de guerra civil no Líbano, 14 gestantes sofreram trauma abdominal penetrante de alta velocidade, onde o projétil atingiu o útero gravídico, com lesões uterinas documentadas ${ }^{6,7}$. Duas destas pacientes morreram devido a envolvimento difuso do tronco e da cabeça. Lesões viscerais ocorreram em oito destas pacientes. Sempre que os projéteis penetraram na parte anterior e acima do nivel do fundo uterino houve lesões viscerais extra-uterinas. A mesma observação ocorreu em pacientes que sofreram ferimentos que tiveram como porta de entrada o dorso. Em contraste com estes resultados, não houve envolvimento visceral em seis mulheres com locais de entrada anterior e abaixo do fundo uterino e em nenhuma delas o projétil chegou a atravessar a parede posterior do útero. Nesta publicação a taxa de mortalidade perinatal atingiu $50 \%$ dos casos ${ }^{7}$. Em geral, nos casos que envolvem acidentes penetrantes, a mortalidade materna atinge aproximadamente $5 \%$ dos casos 6 .

Acredita-se que o deslocamento cefálico das alças intestinais, secundário ao aumento do volume uterino, e o efeito de amortecedor proporcionado pelo útero e seu conteúdo protejam as

\footnotetext{
1 Professor Adjunto da Faculdade de Medicina, Universidade Federal do Rio Grande do Sul - UFRGS - Porto Alegre (RS) - Brasil.

2 Professor adjunto da Faculdade de Medicina, Universidade Federal do Rio Grande do Sul - UFRGS - Porto Alegre (RS) - Brasil.

3 Ginecologista e Obstetra do Serviço de Ginecologia e Obstetrícia do Hospital Mãe de Deus de Porto Alegre - Porto Alegre (RS) - Brasil. 
gestantes nos traumas penetrantes ${ }^{6}$. Este fato explica o menor risco materno e pior risco fetal nos acidentes penetrantes, principalmente durante o segundo e terceiro trimestres da gestação, como foi encontrado nesta série histórica de Fraga et al. Em traumas fechados, o traumatismo fetal é menos comum, pois o feto se encontra protegido pelo complexo formado pelas paredes uterinas e o líquido amniótico. Nos casos de acidente automobilístico, a ocorrência de descolamento prematuro da placenta está associada à gravidade do acidente e à velocidade do veículo ${ }^{8}$.

Durante o atendimento de uma gestante vítima de trauma, além da presença do feto, deve-se também estar atento para as adaptações fisiológicas da gestação, que podem alterar vários parâmetros morfológicos e funcionais no organismo materno.

\section{Conduta nos casos de trauma na gestante}

A conduta nos casos de gestantes traumatizadas, do mesmo modo que fora da gestação, requer um acesso rápido às lesões e a instituição de medidas terapêuticas de suporte à vida no menor tempo possivel ("hora de ouro"), dentro de um tratamento sistematizado que já é consagrado no âmbito da medicina de emergência (Figura 1).

Figura 1 - Protocolo de conduta no trauma em gestante.

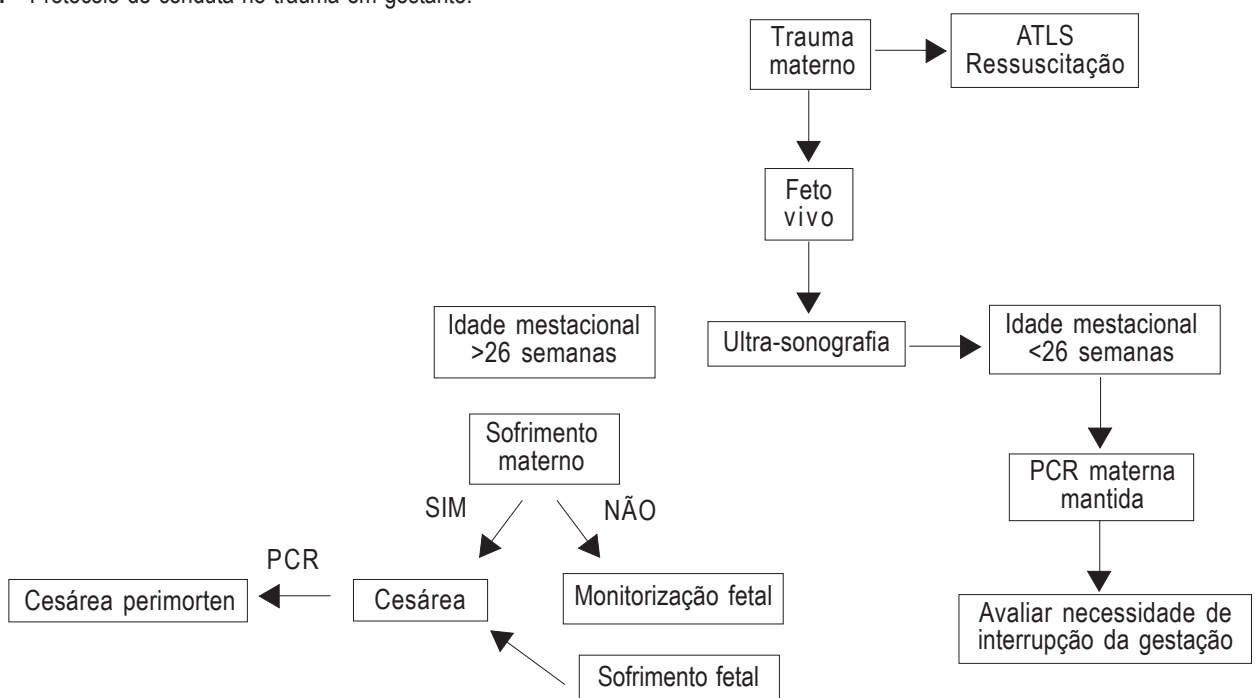

Nota: Considerar a administração de imunoglobulina anti-Rh em mãe Rh negativa.

PCR = parada cárdio-respiratória; ATLS = advanced trauma life support.

O exame inicial em uma emergência deve seguir a seqüência do "ABC" do trauma e a administração de oxigênio. Se há necessidade de suporte ventilatório, deve-se lembrar da conveniência da hiperventilação nestas pacientes. Gestantes no $2^{\circ}$ e $3^{\circ}$ trimestres são suscetiveis, quando na posição supina, a uma profunda hipotensão - sindrome da hipotensão supina - devido à compressão aorto-cava provocada pelo útero (principalmente quando o dorso fetal se situa a direita). Devido ao aumento do volume intravascular e ao aporte sangüíneo diminuído para o feto, a gestante pode perder em torno de 30-35\% do seu volume circulante antes de apresentar taquicardia significativa, hipotensão arterial ou outros sinais e sintomas de hipovolemia. Nessa situação pode-se encontrar um feto chocado e privado de aporte sanguíneo adequado, enquanto as condições maternas parecem estar estáveis na primeira avaliação. Nestas situações devemos evitar, sempre que possivel, a administração de vasopressores na tentativa de restaurar a pressão arterial materna, pois estes fármacos reduzem ainda mais o fluxo útero-placentário, piorando as condições de um feto que já se encontra em uma situação de hipoxemia.

Como o consumo de oxigênio durante a gestação está aumentado, a manutenção de uma PaO2 arterial adequada é particularmente importante na fase de reanimação da mulher grávida. Portanto, toda gestante politraumatizada deve receber $\mathrm{O} 2$ suplementar por cânula nasal, máscara ou entubação endotraqueal. Previamente a procedimentos anestésicos, a administração de cimetidina/ranitidina e metoclopamida por via parenteral pode diminuir a morbidade associada a aspiração de conteúdo gástrico. Portanto, a descompressão gástrica é de suma importância para evitar a aspiração de material gástrico para as vias aéreas em um eventual procedimento anestésico de urgência.

A suspeita de lesão de bexiga e do útero deve ser particularmente lembrada quando associada a uso de cinto de segurança e à identificação de hematoma em faixa na região do baixo ventre. Hematúria franca ou mesmo discreta nem sempre estão presentes durante esta situação.

As conseqüências da hemorragia feto-materna incluem não apenas a anemia fetal e a morte, mas também a aloimunização da paciente Rh-negativa. Mesmo pequenas quantidades de sangue, 
como 0,01 $\mathrm{mL}$ de sangue $\mathrm{Rh}$-positivo, podem sensibilizar pacientes $\mathrm{Rh}$-negativas. A presença de hemorragia feto-materna em uma paciente Rh-negativa justifica a terapêutica com imunoglobulina anti-Rh, preferentemente nas primeiras 72 horas após a ocorrência da hemorragia. Embora o teste de Kleihauer-Betke indique hemorragia feto-materna, um teste negativo não exclui graus de hemorragia menores, mas ainda capazes de sensibilizar a paciente Rh-negativa. É recomendado o rastreio de rotina de hemorragia feto-materna em toda paciente que sofreu traumatismo e que esteja com mais de 11 semanas de gestação. Alternativamente, deve ser considerada a terapia com imunoglobulina anti-Rh para todas as gestantes $\mathrm{Rh}$ negativas vitimas de trauma com risco de hemorragia feto-materna. Trezentos microgramas de imunoglobulina anti-Rh são necessários para cada $30 \mathrm{~mL}$ de hemorragia feto-materna.

As indicações de exames radiológicos em pacientes grávidas são as mesmas do que em nãogestantes. Ao analisarmos uma radiografia da pelve devemos lembrar que a sinfise púbica se encontra alargada, mais notadamente após a 30a semana de gestação. Os espaços entre as articulações sacro-iliacas também tendem a estar afastadas. Estes aspectos devem ser levados em consideração antes de formularmos uma hipótese diagnóstica de fratura em alguma destas estruturas.

Quando houver história de traumas penetrantes, todos os locais de entrada e saída devem ser identificados. A lavagem peritoneal aberta está indicada após trauma, quando os sinais ou sintomas abdominais sugerem sangramento intraperitoneal, quando há choque clínico de etiologia não definida e quando existem múltiplas lesões torácicas ou múltiplas lesões ortopédicas (ACOG, 1991) ${ }^{9}$.

A gestação não deve ser motivo para que se postergue uma laparotomia. Quase sempre a postergação da laparotomia agrava a situação materna e, por conseguinte, a condição fetal. Na maioria dos casos, deve ser tomada uma conduta intervencionista de laparotomia para o controle de ferimentos de arma de fogo no abdome durante a gestação. Profilaxia antibiótica, antitrombótica e para o tétano devem sempre ser lembradas nas gestantes vítimas de traumas. Como a gestação e, em especial, o puerpério são estados de hipercoagulabilidade sangüínea, gestantes e puérperas vítimas de trauma que necessitem imobilização prolongada devem fazer profilaxia do tromboembolismo com heparina e medidas gerais para combater a imobilização. Quando for decidido por uma conduta expectante, a observação materna deverá ser feita em unidade sob vigilância contínua da equipe médica, preferencialmente em UTI em hospital com condições para uma laparotomia de emergência. A monitorização fetal por cardiotocografia é recomendada e a qualquer alteração importante na vitalidade em um feto viável, deve-se considerar a realização de uma cesariana de urgência, independentemente do local onde se encontra a lesão na gestante. Além disso, a monitorização fetal deve sempre ser iniciada quando houver contratilidade uterina que iniciou após o trauma, em fetos com freqüência cardiaca alterada na ausculta clínica, na presença de sangramento por via vaginal, dor uterina, lesão materna grave ou ruptura prematura de membranas ovulares. Se nenhum destes achados está presente em uma gestante após o trauma, uma monitorização cardiotocográfica entre 2 a 6 horas com padrão normal já é suficiente ${ }^{10}$.

O uso do cinto de segurança, embora possa provocar lesões no abdome materno, deve ser incentivado, pois preserva a vida materna e por conseqüência a vida do feto. O cinto de segurança deve ser o de 3 pontos e ser disposto acima e abaixo do abdome gravídico. A tira superior (diagonal) deve cruzar o tórax entre as mamas e ficar disposta acima do útero e a inferior (transversal) deve conter e cruzar transversalmente ao nivel das raizes das coxas. É recomendado haver uma distância segura entre a direção e o útero gravídico.

Hyde et al. ${ }^{11}$, avaliando acidentes automobilísticos, nascimentos e mortalidade fetal no período de 1992 a 1999 no estado de Utah (EUA), concluíram que pacientes utilizando cinto de segurança não tiveram aumento de risco adverso sobre o feto se comparado com pacientes que não tiveram trauma automobilístico. No entanto, gestantes que não utilizaram cinto de segurança durante os acidentes tiveram um risco relativo 1,3 vezes maior para peso baixo ao nascimento do que a população que não teve trauma envolvendo a gestação. Estes autores concluem que as pacientes devem ser estimuladas a utilizar cinto de segurança durante a gestação. A utilização de automóveis com airbags pode ser benéfica, segundo sugerem estudos com pequenas séries de casos ${ }^{12-14}$.

Assuntos de prevenção de acidentes devem ser abordados durante todas as consultas de prénatal ${ }^{10,13}$. Pesquisa de potenciais fatores de risco no lar e no trabalho devem fazer parte dos assuntos discutidos durante toda a gestação pelo médico assistente e sua paciente. A orientação deve abordar a importância de calçar sapatos adequados, sem saltos exagerados, confortáveis e antiderrapantes. É recomendável retirar tapetes não fixos (as bordas podem ficar elevadas criando oportunidade para tropeços). O uso do corrimão é obrigatório em todas as escadas e devem estar em boas condições e sua fixação deve ser sempre revisada. O sedentarismo deve ser combatido em todas as fases da vida da mulher. O sedentarismo favorece a diminuição da habilidade dos movimentos rápidos que são necessários para evitar uma queda, ou torná-la menos traumática, ou pelo menos proteger áreas vitais. No caso da gestante, as quedas de maior perigo para a gestação são as quedas ao solo, sentada e com grande impacto, e os traumas diretos sobre o abdômen. O exercício físico não extenuante deve ser 
encorajado. Uma musculatura tonificada e adequada protege as estruturas mais nobres, além de torná-las mais flexiveis durante uma queda e menos propensas a lesões graves.

A cesariana post-mortem está plenamente justificada diante de um feto vivo e viável intraútero. Quanto menor o tempo entre a parada cardiorespiratória materna e a cesárea, melhores são os resultados peri-natais, indo de $98 \%$ de sobrevida se a intervenção é efetuada até 5 minutos após a morte materna a $25 \%$ se esta ocorre entre 26 e 35 minutos. Explica-se com isso a urgência da conduta e a necessidade de diagnóstico rápido da morte materna. O diagnóstico será embasado clinicamente, na irreversibilidade da parada cardiorespiratória às manobras de ressuscitação ${ }^{15}$. A cesariana deve iniciar em 4 minutos, e o feto ser retirado do útero em 5 minutos, após a parada do coração materno. A cesárea deve ser realizada no mesmo local onde ocorreu o óbito materno.

Se por um lado, a realização da cesárea post-mortem é perfeitamente justificável, encontrando inteiro respaldo sob ponto de vista ético e médico-legal, o mesmo não se pode afirmar da cesárea realizada em gestante gravemente enferma. Nesta situação, avalia-se o feto por cardiotocografia e, constatado o sofrimento fetal com feto viável, indica-se a cesárea. Nestas situações poderá mesmo haver uma melhora clínica materna após o procedimento. O parto via alta freqüentemente tem um efeito de reanimação materna, por diminuir o volume uterino e melhorar o retorno venoso e o débito cardíaco ${ }^{16-18}$.

Um dos pontos estudados por Fraga et al., nesta edição, é a questão de termos um marcador de prognóstico para morbimortalidade materno-fetal. Os escores descritos para trauma fora da gestação, como Escore de Trauma Revisado (Revised Trauma Score ou RTS), Índice de Gravidade da Lesão (Injury Severity Score ou ISS), TRISS (Probabilidade de Sobrevida) e o Índice de Trauma Abdominal (Abdominal Trauma Index ou ATI), não tiveram poder para serem considerados como indicadores de prognóstico fetal. O único fator de estudo que encontrou significância como prognóstico fetal foi a presença de lesão uterina. Talvez haja a necessidade de construirmos um índice próprio para traumas em gestantes, que preveja lesões gerais e próprias para a gestante, pois há uma forte necessidade destes índices frente aos números crescentes de traumas em gestantes no nosso meio, seja pelo aumento dos acidentes automobilísticos, seja pela agressividade de nossa sociedade.

\section{Referências}

1. Guerin YLS, Ramos JGL, Costa SHAM. Trauma na paciente obstétrica. Femina. 2002;30(10):743-8.

2. Ministério da Saúde. Manual dos comitês de mortalidade materna.//3a ed. Brasília (DF); 2005.

3. Fildes J, Reed L, Jones N, Martin M, Barrett J. Trauma: the leading cause of maternal death. J Trauma. 1992;32(5):643-5.

4. Esposito TJ. Trauma during pregnancy. Emerg Med Clin North Am. 1994;12(1):167-99.

5. Corsi PR, Rasslan S, Oliveira LB, Kronfly FS, Marinho VP. Trauma na gestante: análise da mortalidade materna e fetal. Rev Col Bras Cir. 1999;26(2):79-83.

6. Stone IK. Trauma in the obstetric patient. Obstet Gynecol Clin North Am. 1999;26(3):459-67.

7. Awwad JT, Azar GB, Seoud MA, Mroueh AM, Karam KS. High-velocity penetrating wounds of the gravid uterus: review of 16 years of civil war. Obstet Gynecol. 1994;83(2):259-64.

8. Reis PM, Sander CM, Pearlman MD. Abruptio placentae after auto accidents. A case-control study. J Reprod Med. 2000;45(1):6-10.

9. ACOG educational bulletin. Obstetric aspects of trauma management. Number 251, September 1998 (replaces Number 151, January 1991, and Number 161, November 1991). American College of Obstetricians and Gynecologists. Int J Gynaecol Obstet. 1999;64(1):87-94.

10. Connolly AM, Katz VL, Bash KL, McMahon MJ, Hansen WF. Trauma and pregnancy. Am J Perinatol. 1997;14(6):331-6.

11. Hyde LK, Cook LJ, Olson LM, Weiss HB, Dean JM. Effect of motor vehicle crashes on adverse fetal outcomes. Obstet Gynecol. 2003;102(2):279-86.

12. Pearlman MD. Motor vehicle crashes, pregnancy loss and preterm labor. Int J Gynaecol Obstet. 1997;57(2):127-32.

13. Pearlman MD, Klinich KD, Schneider LW, Rupp J, Moss S, Ashton-Miller J. A comprehensive program to improve safety for pregnant women and fetuses in motor vehicle crashes: a preliminary report. Am J Obstet Gynecol. 2000;182(6):1554-64.

14. Pearlman MD, Phillips ME. Safety belt use during pregnancy. Obstet Gynecol. 1996; 88(6):1026-9.

15. Ministério da Saúde. Urgências e emergências maternas: guia para diagnóstico e conduta em situações de risco de morte materna.//2a ed. Brasília (DF); Ministério da Saúde/FEBRASGO; 2000. p. 95-102.

16. Katz VL, Dotters DJ, Droegemueller W. Perimortem cesarean delivery. Obstet Gynecol. 1986;68(4):571-6.

17. Morris JA Jr, Rosenbower TJ, Jurkovich GJ, Hoyt DB, Harviel JD, Knudson MM, et al. Infant survival after cesarean section for trauma. Ann Surg. 1996;223(5):481-8.

18. Tedesco JJA. A grávida no trânsito. In: Tedesco JJA, editor. A grávida suas indagações e as dúvidas do obstetra. São Paulo: Atheneu; 2000. p. 97-109. 